University of Washington Tacoma

UW Tacoma Digital Commons

SIAS Faculty Publications

School of Interdisciplinary Arts and Sciences

$4-1-2006$

\title{
Off the Couch and Onto the Streets: Toward an Ethnographic Psychoanalysis
}

Kima Cargill

University of Washington Tacoma, kcargill@uw.edu

Follow this and additional works at: https://digitalcommons.tacoma.uw.edu/ias_pub

\section{Recommended Citation}

Cargill, Kima, "Off the Couch and Onto the Streets: Toward an Ethnographic Psychoanalysis" (2006). SIAS Faculty Publications. 75. https://digitalcommons.tacoma.uw.edu/ias_pub/75

This Article is brought to you for free and open access by the School of Interdisciplinary Arts and Sciences at UW Tacoma Digital Commons. It has been accepted for inclusion in SIAS Faculty Publications by an authorized administrator of UW Tacoma Digital Commons. 


\section{Running head: OFF THE COUCH AND ON THE STREETS}

Off the couch and on the streets: Toward an ethnographic psychoanalysis

\section{Kima Cargill}

Interdisciplinary Arts and Sciences Program

University of Washington, Tacoma 


\begin{abstract}
Psychoanalysis has much to gain by incorporating ethnographic methods into its repertoire. Recent works in ethnographic psychoanalysis demonstrate how psychoanalysis stands to function better as both community intervention and participatory action research. This article describes the historical convergence between psychoanalysis and cultural anthropology and situates ethnographic psychoanalysis within interdisciplinary theory and practice.
\end{abstract}


Off the couch and on the streets: Toward an ethnographic psychoanalysis

Psychoanalysis and cultural anthropology are old bedfellows - disciplines who've fallen into the habit of breaking up and getting back together without really figuring out how to live with one another. Cultural anthropology, to be fair, has done a better job at forging rapprochement, while psychoanalysis has played the role of the coy, pouty lover, unwilling to give up any ground for the reconciliation.

Ever since Geertz announced that genres were becoming blurred (1983), cultural anthropology has been successful at integrating psychoanalysis into ethnographic methodology, thereby constructing a matrix of cultural, linguistic, and intrapsychic forces in the understanding of behavior (Brody \& Newman, 1981; Ewing, 1987; Heald \& Deluz, 1994; Ingham, 1996). Psychoanalysis, on the other hand, has made little effort to incorporate anthropology, or more specifically, ethnography, into its repertoire of methods. Yet by doing so, we stand to gain much. Not only does the use of ethnographic methods promise to considerably widen the scope of psychoanalytic inquiry, it also provides a more complete way of understanding the individual within cultural and linguistic contexts. Incorporating ethnography is consistent with psychoanalysis's move toward the study of meaning as shaped by culture and collectively shared and transmitted symbols. A broadening of the psychoanalytic gaze can serve to partially rescue psychoanalysis from the marginalization it has suffered in the academic social sciences, as well as bring psychoanalytic thought into the lives and communities of those who are not academics, analysts and analysands.

The central argument of this series of field notes, then, is to advance an ethnographic psychoanalysis, an interdiscipline comprised of psychoanalysis and cultural anthropology, which offers social utility and is applicable outside of the consulting room. Such an approach brings to bear the theories and methods of both disciplines, thereby acting as a "corrective" to some of the historical shortcomings of each discipline by itself (Klein \& Newell, 1997).

Historically psychoanalysis has been accused, quite rightly, of advancing a decontextualized analysis of the individual without taking into account sociocultural phenomena in the construction of 
subjective and intersubjective narratives and realties. The emergence of the interpersonal school, object relations, and the Lacanian school has re-crafted traditional psychoanalytic thinking, rooted in drive and ego psychology, to allow for a richer and more comprehensive understanding of the fluid dynamics between selves and their cultural, communal, and linguistic landscapes. While the clinical case study remains the hallmark method of the discipline, psychoanalysis has epistemologically moved away from the study of the bounded individual (a one person psychology) to a more complete understanding of selves and their linguistic and cultural landscapes (a three person psychology) (Kernberg, 1997). This three person psychology, however, still functions almost exclusively within the context of the analytic dyad - a rarefied and privileged space for the application of psychoanalytic theory. Rarely or never does the psychoanalyst venture into the analysand's milieu to make meaning of his or her world. Neither our methodology, then, nor our principal context, have developed in a way that is commensurate with the development of more recent theories and epistemologies.

The goal of ethnography was originally to understand a culture on its own terms, to represent meaning from the "native's point of view" (Malinowski, 1922). In his work on the Trobiand Islanders, Malinowski integrated interviewing with participant-observation, thereby creating modern ethnography (Erickson, 1986). Because of the heavy emphasis on describing cultural narratives and practices, cultural anthropology, in contrast to psychoanalysis, has been historically weak at understanding the subjectivities of the individual (Heald \& Deluz, 1994, p. 3).

The evolution of both psychoanalysis and cultural anthropology has thus fertilized the intellectual terrain and has allowed the creation of two new interdisciplines which bring to bear the strengths of both on the study of human beings. Ethnographic psychoanalysis, then, is comprised of psychoanalysts and psychoanalytic theorists who rely on ethnographic methods, while its cousin, psychological anthropology, typically refers to the opposite: scholars trained as anthropologists who rely on psychoanalytic theories. 
Ethnographic psychoanalysis can be contextualized both as an interdiscipline and as a constituent of the qualitative psychology movement. While there are several widely used definitions of interdisciplinarity, a review of the literature suggests that it is often defined as either: 1) the integration of more than one discipline in order to encourage the cognitive synthesis of diverse theories and methodologies (Hursh \& et al., 1983); or 2) the use of multiple disciplines to more adequately examine a set of social problems or issues. Klein and Newell (1997) define interdisciplinary studies as "a process of answering a question, solving a problem, or addressing a topic that is too broad or complex to be dealt with adequately by a single discipline or profession." The heart of interdisciplinarity is the interplay of perspectives that occurs in balancing depth, breadth, and synthesis. Depth insures the necessary disciplinary, professional, and interdisciplinary knowledge and information for the task at hand. Breadth insures a multidisciplinary variety of perspectives. Synthesis insures integrative process and construction of a holistic perspective that is greater than the simple sum of its parts (pp. 393-394, 404-407). Herein lies arguably the greatest strength of interdisciplinarity: the capacity to deal with complex sociopolitical phenomena.

Too, interdisciplinarity reflects underlying epistemological assumptions about knowledge itself. The shift away from strict disciplinary lines is indicative of the hermeneutic discourse among the disciplines, reflecting a circular and dynamic dialogue among historically different ways of knowing. This shift has emerged over the past several decades in tandem with postmodernism. Broadly speaking, interdisciplinarity reflects the postmodern idea that absolute foundations for attaining knowledge are inherently problematic (Mourad, 1997). "Cross-disciplinary inquiries are an effort to pursue knowledge without being essentially constrained by the structure and content of a single discipline, including subject matter, predominate theories, typical methods, or primary schools of thought."

In recent years, in spite of the intensive pressures to situate psychology within the sciences, many scholars have nonetheless moved toward a more tolerant stance of qualitative research, exemplified most recently by the American Psychological Association's publication of Qualitative 
Research in Psychology (Camic, Rhodes, \& Yardley, 2003), one of the first of such volumes to be published by the flagship organization which controls what counts as legitimate knowledge in psychology.

"Research in psychology, like research in other fields, is shaped by ideas and ideals regarding matters of method. By ideas and ideals I mean beliefs about what is legitimate to study and how such study should be done. Psychologists, like others, embrace "religions" that they believe define the right way to do things. The power - and the conflicts — among these religions is nowhere more apparent than in debates about the legitimacy of qualitative research in psychology, a field that has struggled so desperately to be regarded as a science” (Eisner, 2003, p. 17).

While ethnographic psychoanalysis is not prolific in the psychoanalytic literature, there are a number of rich examples which demonstrate the value of the approach. Egan, for example, (2003) examines patriarchy, feminine resistance, desire, and fantasy through an ethnography in two New England exotic dance clubs over the course of four years. Stoller (1991) enters the world of consensual S\&M and documents the dynamics of erotic excitement. Cohen (2001) uses ethnography in the Skid Row District of Los Angeles to understand how the mentally ill homeless make meaning out of their lives in the face of marginalization, poverty, and violence.

Most notably, Ainslie $(1995,2003,2004)$ has used ethnographic psychoanalysis for the past decade in studying small communities in Texas characterized by racial discord. In Anson, Texas, he explored the post-Jim Crow reality in a community that had been entirely white prior to the Civil Rights Era but by the 1990's had grown into a diverse community with Latinos constituting one third of its residents . When Ainslie first visited Anson, it was ostensibly to investigate the community's controversy over whether or not the high school should have had a school dance. As it turned out, the dance controversy was the "presenting symptom", one which symbolized deep-seated and more primitive conflicts within the community surrounding the anxieties provoked by racial integration and facing "Otherness". In Hempstead, Texas, Ainslie explores the story of this small community and how it dealt with forced desegregation following Brown vs. Board of Education. More recently, Ainslie uses 
ethnographic psychoanalysis in Jasper, Texas as both intervention and analysis of a community torn by the trauma of the modern day lynching of James Byrd. (See Whilde, this issue, for more detail on ethnographic psychoanalysis in Jasper.) "All three of these communities have been entered with a notable uncertainty about what it is that would be found in them, yet that ambiguity has not been unsettling. On the contrary, it is quite familiar, being the very essence of a psychoanalytic approach to patients' stories/lives as we learn about them in the consulting room. This unstructured, open-ended attitude or orientation leads to extended engagements. In each of these communities, the projects have revolved around a core of long-term relationships. [Ainslie] spent three years going to Anson, two-anda-half years going into Hempstead, and it was two-and-a-half years ago that he first went into Jasper, a work that is still ongoing. Meaningful engagements take time to develop. Anthropologists and psychoanalysts know this well,” (Ainslie \& Brabeck, 2003, pp. 42-43).

Ethnographic psychoanalysis, much like participatory action research, has the potential to both study communities, but also to intervene in and empower them. Participatory action research, or PAR, is understood to be research-based social action projects dedicated to documenting and understanding individuals, communities, and their social problems (Fine et al., 2003). Psychoanalysis, no stranger to the talking cure, has as much to offer communities in pain as it does to individuals in pain. This kind of intervention or "treatment" functions to reconfigure personal and community narratives by giving voice to the marginalized.

In 1999 I attended the screening of Ricardo Ainslie's psychoanalytic documentary of Hempstead, Texas, entitled, "Crossover". Following the forced schools desegregation, the former Black high school was torn down, and with it, all traces of its students' accomplishments, including trophies and awards, were lost. This loss represented a trauma for the African-American community that was collectively repressed and excommunicated from consciousness. In the documentary interviews it was clear that there was still tremendous pain, lingering racism, and shame among both Whites and African-Americans in this community. The documentary, however, re-constructed a 
narrative through the voices of the townspeople in which many felt freer to express remorse, contrition, and sorrow over the social injustices that occurred. Through the public telling of these narratives, the unconscious collective trauma held by the African-American community was made conscious, reintegrating this painful past into the contemporary discourse in a manner that served a restorative psychic function. Much like a successful analysis, the documentary served as an interpretive mirror which helped the community of Hempstead reintegrate split-off, disavowed parts of the self.

At the end of the screening, during the question and answer period, the Reverend Thomas, a prominent community leader, who along with fifty-five other residents of Hempstead, Texas made the two hour journey to Austin, stood up, and with tears in his eyes, and publicly thanked Ainslie for telling their story. Not just for telling the story, but for "getting it" in all of the torment, complexity, pain, and nostalgia, in a way that only an analyst can. Reverend Thomas is not a man who would likely ever have the opportunity or desire to seek clinical psychoanalysis - nothing could be farther from his cultural landscape. Yet, by way of this ethnography and its resulting documentary, the couch, so to speak, was brought to him. It was brought to him on his terms, in his social milieu, in a way that brought reflection, catharsis, and healing to him, his congregation, and his community. With such potential, why then, is psychoanalysis often viewed by the academy much like the fabled, flightless Dodo Bird, ridiculed because its small wings were too weak to lift its heavy body off the ground, ultimately leading to its extinction?

To be sure, clinical psychoanalysis is often viewed as elitist, self-indulgent, insensitive to cultural diversity, and as a treatment available only to the "worried well"(McWilliams, 2000). With the increasing marginalization of psychoanalysis (Auchincloss \& Michels, 2003; Hornstein, 1992; McWilliams, 2000), both by the perceived failure of psychoanalysis to demonstrate empirical validity, as well as the relegation of clinical psychoanalytic study largely to free-standing institutes, psychoanalysis has much to gain by moving itself outside the consulting room and into communities. Attempting to quantify psychoanalytic approaches within a positivist-empirical framework is not the answer. 
Expanding our methodologies from the case study into other codified techniques in the human sciences, is. One avenue for accomplishing this is by incorporating the ethnographic method as a major tool of inquiry. By embracing psychoanalysis as a human science and a social science rather than fighting the tide of psychological science, we stand to reconfigure psychoanalysis as a valid, contemporary, and relevant discipline. 


\section{References}

Ainslie, R. (1995). No dancin' in Anson: An American story of race and social change. Northvale, N.J.: J. Aronson.

Ainslie, R. (2004). Long dark road: Bill King and murder in Jasper, Texas. Austin: University of Texas Press. Ainslie, R., \& Brabeck, K. (2003). Race murder and community trauma: Psychoanalysis and ethnography in exploring the impact of the killing of James Byrd in Jasper, Texas. Journal for the Psychoanalysis of Culture \& Society, 8(1), 42-50.

Auchincloss, E. L., \& Michels, R. (2003). A reassessment of psychoanalytic education: Controversies and changes. International Journal of Psychoanalysis, 84(2) Apr 2003, 387-403.

Brody, E. B., \& Newman, L. F. (1981). Ethnography and psychoanalysis: Comparative ways of knowing. Journal of the American Academy of Psychoanalysis \& Dynamic Psychiatry, 9(1), 17-32.

Camic, P. M., Rhodes, J. E., \& Yardley, L. (2003). Qualitative research in psychology: Expanding perspectives in methodology and design. Washington, DC: American Psychological Association.

Cohen, A. (2001). The search for meaning: Eventfulness in the lives of homeless mentally ill persons in the Skid Row district of Los Angeles. Culture, Medicine and Psychiatry, 25(3), 277-296.

Egan, R. (2003). I'll be your fantasy girl, if you'll be my money man: Mapping desire, fantasy and power in two exotic dance clubs. Journal for the Psychoanalysis of Culture \& Society, 8(1), 109-120.

Eisner, E. W. (2003). On the art and science of qualitative research in psychology. In P. M. Camic, J. E. Rhodes \& L. Yardley (Eds.), Qualitative research in psychology: Expanding perspectives in methodology and design (pp. 17-29). Washington, DC: American Psychological Association.

Erickson, F. D. (1986). Qualitative methods in research on teaching. In M. C. Wittrock (Ed.), Handbook of research on teaching (3rd ed.). New York: Macmillan.

Ewing, K. P. (1987). Clinical psychoanalysis as an ethnographic tool. Ethos, 15(1), 16-39.

Fine, M., Roberts, R., Torre, M., Upegui, D., Bowen, I., Boudin, K., et al. (2003). Participatory Action Research. In P. M. Camic, J. E. Rhodes \& L. Yardley (Eds.), Qualitative research in psychology: 
Expanding perspectives in methodology and design (pp. 173-198). Washington, DC: American

Psychological Association.

Geertz, C. (1983). Local knowledge: further essays in interpretive anthropology. New York: Basic Books.

Heald, S., \& Deluz, A. (1994). Anthropology and psychoanalysis: An encounter through culture. New York: Routledge.

Hornstein, G. A. (1992). The return of the repressed: Psychology's problematic relations with psychoanalysis, 1909-1960. American Psychologist, 47(2), 254-263.

Hursh, B., \& et al. (1983). An Interdisciplinary Model to Implement General Education. Journal of Higher Education, 54(1), 42-59.

Ingham, J. M. (1996). Psychological anthropology reconsidered. Cambridge [England] ; New York: Cambridge University Press.

Kernberg, O. F. (1997). The nature of interpretation: Intersubjectivity and the third position. Annual of Psychoanalysis, 25, 97-110.

Klein, J. T., \& Newell, W. H. (1997). Advancing interdisciplinary studies. In J. G. Gaff \& J. L. Ratcliff (Eds.), Handbook of the Undergraduate Curriculum: A Comprehensive Guide to the Purposes, Structures, Practices, and Change. (pp. 393-415). San Francisco, CA: Jossey-Bass Publishers.

Malinowski, B. (1922). Argonauts of the western Pacific. London,: G. Routledge \& Sons.

McWilliams, N. (2000). On teaching psychoanalysis in antianalytic times: A polemic. American Journal of Psychoanalysis, 60(4), 371-390.

Mourad, R. P., Jr. (1997). Postmodern interdisciplinarity. Review of Higher Education, 20(2), 113-140.

Stoller, R. J. (1991). Pain and passion: A psychoanalyst explores the world of S \& M. New York: Plenum Press. 